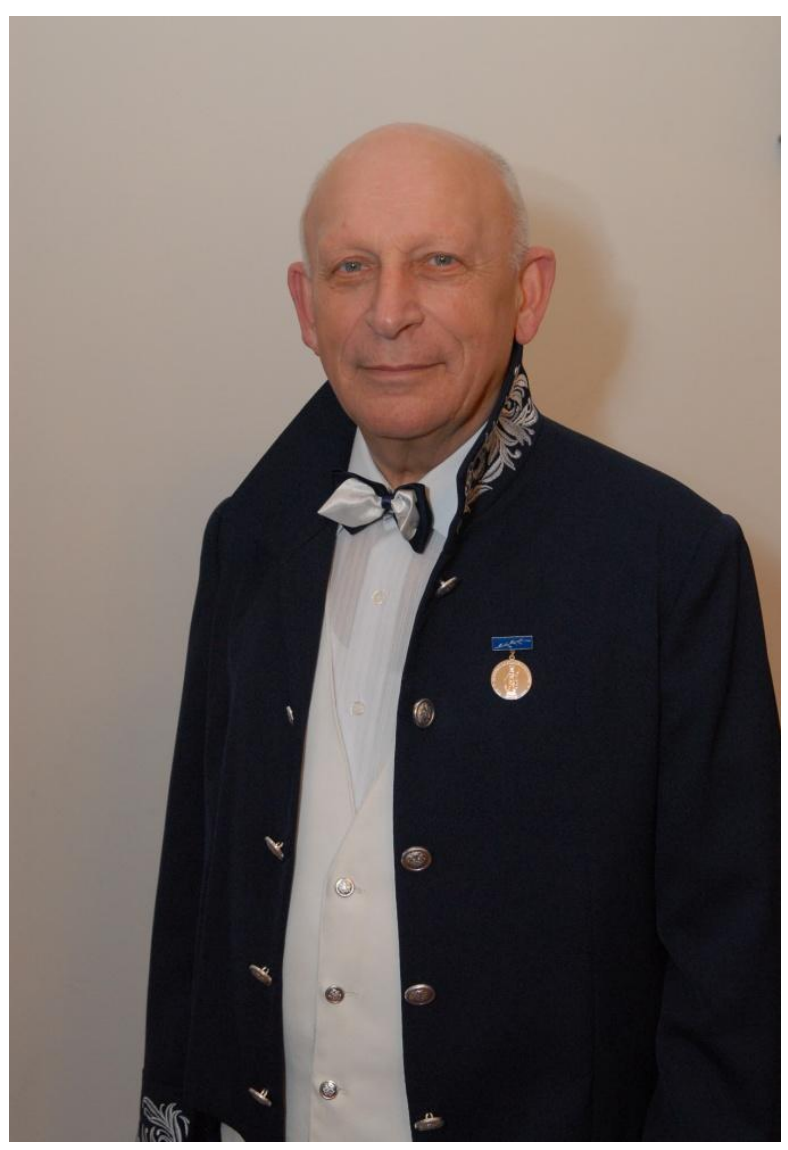

(06.06.1936 - 24.03.2017)

\title{
EULOGY TO A MAN OF EXCELLENCE: ACADEMICIAN PAVEL VLAD
}

Academician Pavel Vlad is one of the remarkable Moldovan personalities, who founded new research directions in Moldovan science, thus contributing to its development and recognition worldwide. It is significant that, like no one else, Professor Pavel Vlad perfectly guessed the trends of time, focusing on the subtle problems of the natural compounds chemistry. Academician Pavel Vlad has brought essential contributions to the field of bioorganic chemistry, expanding the fame of Republic of Moldova far from its borders by the remarkable achievements of the promoted scientific school - School of bioorganic chemistry, chemistry of natural and biologically active compounds at the Institute of Chemistry of Academy of Sciences of Moldova.

The extensive fundamental research carried out within the academic school of Professor Pavel
Vlad was oriented towards development of the general methods for determining the absolute configuration of a series of labdane diterpenoids and their conversion into bi-, tri- and tetracyclic compounds; proposing new, universal methods for the synthesis of tetrahydrofurans from 1,4glycols, nor-alcohols from cyclic olefins, olefins from acetates of tertiary alcohols, glycols from lactones, unsaturated alcohols from the monoacetates of di-tertiary glycols, and dienones by photo-dehydrogenation of the unsaturated cyclic ketones; elaboration of efficient ozonolytic methods for preparation of norlabdane compounds. The scientific school, founded by Academician Pavel Vlad, holds the leading position in the study of superacidic cyclization reaction of terpenoids. Regularities of this reaction were set for various classes of terpene 
compounds (alcohols, their acetates, acids, esters, phenylsulfones etc.). Academician Pavel Vlad and co-workers have proposed a new theory to assess the structure-odour relationships of compounds endowed with amber and musk smell, which found a high appreciation from a large number of scholars from abroad. This theory offers the possibility of synthesizing compounds endowed with fine amber and musk odour.

The international appreciation of the high level of research conducted within the academic school of Academician Pavel Vlad is based on their polyvalent character, modern and reasoned conclusions, documenting elaborations and reproducibility of the results.

The results of Academician Pavel Vlad research, over the years, have been summarized in over 400 scientific publications, including three monographs, four textbooks, 16 synthesis articles and 52 patents, with participation in 45 international conferences and symposiums, etc.

A great part of the scientific activity of Academician Pavel Vlad was devoted to practical elaborations. His inventions were awarded with the Diplomas and Medals at VDNKh in MSSR (1978, 1984), two Bronze Medals (1981) and a Silver Medal (1984) at VDNKh in USSR, and State Agency on Intellectual property (AGEPI) mentioning Diplomas (1996-2001). The cycle of inventions "Odoriferous compounds for perfumery, cosmetics and tobacco industry based on local renewable raw material - production waste" has won 4 Gold Medals and a Silver Medal at the international exhibitions of inventions of Geneva, Switzerland (1999, 2001), and "EUREKA" in Brussels, Belgium (1995, 1996, 2001). Academician Pavel Vlad was awarded the Gold Medal of World Intellectual Property Organization (WIPO) "Outstanding Inventor" in 2001.

Under the guidance of Professor Pavel Vlad 3 theses of Doctor Habilitatus and 16 theses of Doctor in chemistry were prepared and defended.

Academician Pavel Vlad harmoniously combined professional and managerial activities. He has always promoted truth and fairness; he used to speak directly what he thought, calmly and sparingly; he respected the academic spirit, and he was a man you could rely on.

Being highly appreciated for his professional qualities and scientific achievements, Academician Pavel Vlad obtained the academic title of Professor in 1990, soon becoming a full member of the Academy of Sciences of Moldova in 1992.

Academician Pavel Vlad is twice a winner of the State Prize, and also winner of the WIPO Award. He was awarded the Order of the Republic, the Insignia of Honour Order, the Valour in Work Medal and Dimitrie Cantemir Medal of A.S.M. In 2011 he was awarded the honorary title "Man Emeritus of the Republic of Moldova".

Academician Pavel Vlad was a member of Editorial Board of Chemistry Journal of Moldova. General, Industrial and Ecological Chemistry since its foundation (2006).

The serene image of Academician Pavel Vlad will always remain alive in our hearts.

Academician Gheorghe DUCA

President of the Academy of Sciences of Moldova Editor-in-Chief of Chemistry Journal of Moldova

Corresponding member Tudor LUPASCU, Director of the Institute of Chemistry of Academy of Sciences of Moldova 